\title{
El maracuyá en Florida ${ }^{1}$
}

\section{Mark Bailey, Ali Sarkhosh, Amir Rezazadeh, Joshua Anderson, Alan Chambers y Jonathan Crane; traducción por Jonathan Clavijo-Herrera²}

\section{Nombre científico: Passiflora edulis Sims}

Nombres comunes: passion fruit (inglés), parcha y maracuyá (español), maracujá (portugués), lilikoi (hawaiano), buah susu (malya), linmangkon (tailandés), chum bap (vietnamita). En la Figura 1 se muestra la flor.

Familia: Passifloraceae

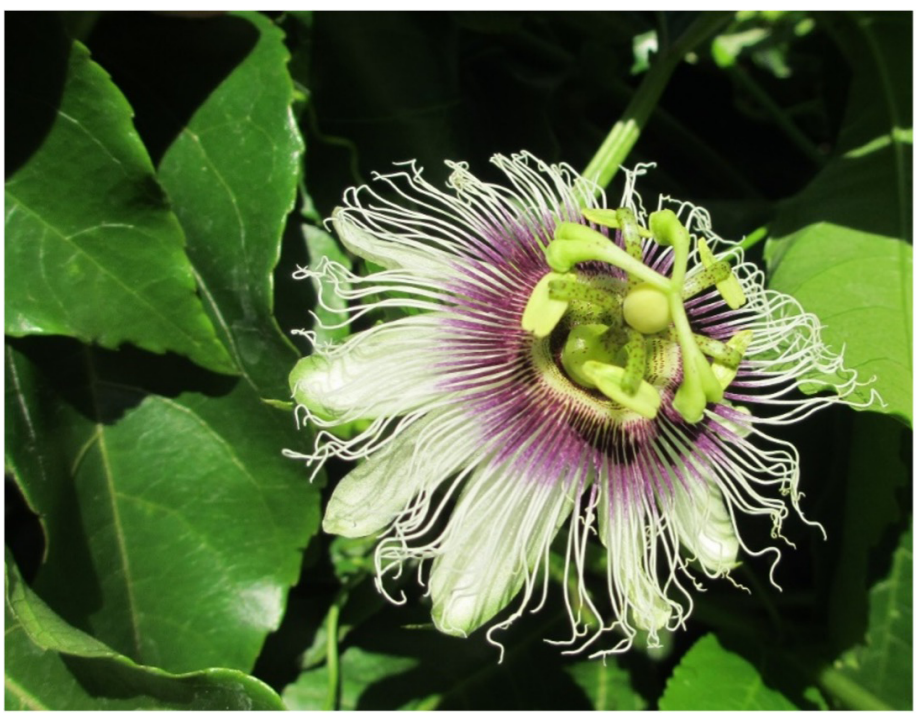

Figura 1. Flor de maracuyá.

Créditos: Mark Bailey, UF/IFAS
Distribución: Varias especies y cultivares de maracuyá son cultivadas en todas las zonas tropicales y subtropicales del mundo.

Importancia: La producción estimada anual de maracuyá es de 1,5 millones de toneladas métricas, con Brasil como el principal productor mundial (Altendorf 2018). Otros grandes productores son Colombia, Perú, Ecuador, Australia, Nueva Zelanda, Indonesia y algunos países africanos. En los Estados Unidos, el maracuyá se cultiva comercialmente en Florida, Hawái, Puerto Rico, y California.

\section{Historia del Maracuyá}

El primer informe europeo de maracuyá fue hecho por Cieza de León en 1553, cuando era funcionario civil en Colombia (Ulmer y MacDougal 2004). Cieza la llamó "granadilla" (pequeñas granadas), la cual era potencialmente Passiflora ligularis. En 1569, Nicolás Monardes, médico en España, asoció la morfología del maracuyá con la crucifixión de Cristo. Posteriormente, la flor de maracuyá fue utilizada por los primeros misioneros en Brasil como una ayuda ilustrativa en un esfuerzo por convertir a la población indígena al cristianismo. Específicamente, se la denominó como "la flor de las cinco heridas" para representar la crucifixión de Cristo. El simbolismo perduró tanto, que Carl Linnaeus estableció el nombre científico

1. Este documento es HS1406s, parte de una serie elaborada por el Departamento de Ciencias Hortícolas, UF/IFAS Extension. Publicado por primera vez en septiembre 2021. Visite el sitio web de EDIS en https://edis.ifas.ufl.edu.

2. Mark Bailey, agente de Extensión I para granjas pequeñas, agricultura sostenible y sistemas alimentarios, UF/IFAS Extension Marion County; Ali Sarkhosh, profesor asistente y especialista en Extensión, Departamento de Ciencias Hortícolas, Gainesville; Amir Rezazadeh, agente de Extensión II para múltiples condados en árboles frutales y cultivos de campo, UF/IFAS Extension Indian River County; Joshua Anderson, estudiante de posgrado; Alan Chambers, profesor asistente; y Jonathan H. Crane, profesor y especialista en cultivo de frutas tropicales, Departamento de Ciencias Hortícolas, UF/IFAS Tropical Research and Education Center. Traducción por Jonathan Clavijo-Herrera, estudiante de doctorado, Departamento de Ciencias Hortícolas; UF/IFAS Extension, Gainesville, FL 32611.

The Institute of Food and Agricultural Sciences (IFAS) is an Equal Opportunity Institution authorized to provide research, educational information and other services

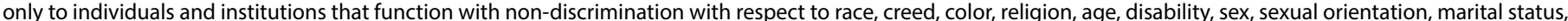
national origin, political opinions or affiliations. For more information on obtaining other UF/IFAS Extension publications, contact your county's UF/IFAS Extension office. U.S. Department of Agriculture, UF/IFAS Extension Service, University of Florida, IFAS, Florida A \& M University Cooperative Extension Program, and Boards of County Commissioners Cooperating. Nick T. Place, dean for UF/IFAS Extension. 
del género como Passiflora (palabra en latín para "flor de la pasión”) en 1737 (Kugler y King 2004).

\section{Taxonomía del Maracuyá}

El maracuyá es una enredadera perenne de ciclo corto que produce una fruta aromática y tropical. Las especies comúnmente cultivadas en los Estados Unidos son el maracuyá púrpura (Passiflora edulis) y, en menor medida, el maracuyá amarillo ( $P$. edulis flavicarpa). Actualmente, la evidencia sugiere que $P$. edulis y $P$. edulis flavicarpa son morfológica y genéticamente de la misma especie. Por tanto, $P$. edulis es la designación preferida de especies y género (Bernacci et al. 2008; Silva y Santos 2020). P. edulis es originaria de las regiones de Brasil, Paraguay, y el norte de Argentina, y se cultiva en todo el mundo donde el clima es apropiado (Ulmer y MacDougal 2004). Existen más de 500 especies dentro del género Passiflora, pero sólo un pequeño número produce fruta comestible. La mayoría son enredaderas portadoras de zarcillos, y muchas tienen valor ornamental.

Mientras $P$. edulis se cultiva con mayor frecuencia, existen también otras especies dentro del género Passiflora que son de importancia agrícola: el maracuyá dulce ( $P$. alata), que tiene un fruto entre amarillo y naranja; granadilla dulce ( $P$. ligularis), con una cáscara similar a la de naranja cuando está madura; limón de agua ( $P$. laurifolia), que tiene un fruto amarrillo o anaranjado y notas de sabor a coco; calabaza dulce (P. maliformis), con un fruto redondo de color amarillo-marrón; y granadilla gigante ( $P$. quadrangularis), que tiene un fruto de color amarillo verdoso de hasta 8 pulgadas de largo. $P$. incarnata, comúnmente llamada maypop o "flor de la pasión" (no debe confundirse con $P$. edulis), es la especie más resistente al frío, nativa del sur de los Estados Unidos,y tiene un fruto entre amarillo y verde, que puede ser insípido o ligeramente dulce.

\section{Adaptación}

Las plantas de maracuyá se adaptan a climas tropicales y semitropicales, como Florida. Las zonas de aclimatación del Departamento de Agricultura de los Estados Unidos (USDA) $9 \mathrm{~b}$ y superiores son recomendadas para P. edulis. En condiciones favorables, las nuevas plantas crecen vigorosamente, y normalmente comienzan a producir flores y frutos un año después de la plantación (Figura 2). La vida útil de una planta productiva de maracuyá suele ser de unos tres a cuatro años, aunque ocasionalmente pueden vivir más tiempo. Se dice que el verdadero maracuyá púrpura se adapta a ambientes de altura en los trópicos. Por el contrario, los maracuyás amarillos e híbridos entre morado y amarillo se consideran mejor adaptados a lugares más bajos y cálidos. El maracuyá crece mejor en suelos bien drenados y tiene un sistema radicular poco profundo. Por tanto, estas plantas tienen resistencia limitada a la sequía e inundaciones (Departamento de Agricultura y Pesca de Queensland 2016). Las plantas maduras con follaje denso pueden tolerar temperaturas ligeramente por debajo del punto de congelación, con cierta pérdida de follaje. Sin embargo, la exposición a temperaturas cercanas a los 25 grados Fahrenheit puede resultar en la muerte completa de la planta por encima del nivel del suelo, y podría no retoñar a partir del tejido bajo tierra (Campbell et al. 1977).

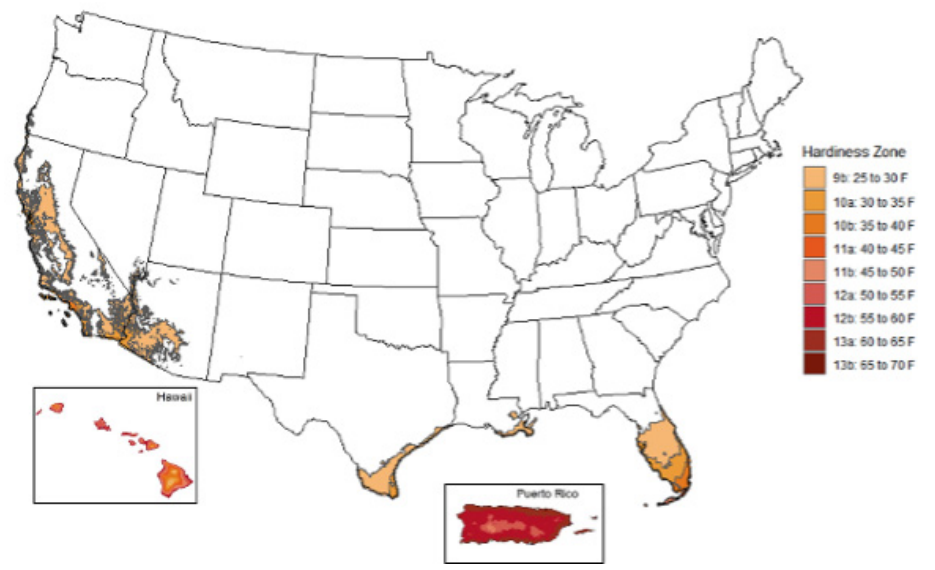

Figura 2. Zonas de aclimatación del Departamento de Agricultura de los Estados Unidos (USDA) apropiadas para el cultivo P. edulis; datos obtenidos de USDA ARS OSU (2012).

El maracuyá no está incluido en la lista de malezas nocivas del USDA de Florida o en la lista de Especies de Plantas Invasivas del Consejo para Plagas Vegetales Exóticas de Florida.

\section{Descripción de la Planta}

Hábito de crecimiento: El maracuyá crece como lianas perennes o enredaderas leñosas que alcanzan una gran longitud. A menudo, cubren las copas de árboles maduros cuando crecen naturalmente (Figura 3). Mientras que la longitud total de las plantas maduras puede superar los 100 pies, también pueden crecer más de 35 pies en un solo año. A medida que el nuevo crecimiento emerge de las puntas de la planta, los botones florales emergen junto con hojas y zarcillos jóvenes. Los zarcillos de la enredadera le ayudan a escalar y asegurarse, mientras envuelven objetos con los que entran en contacto. Las enredaderas que crecen bajo sombra o sombra parcial suelen perder sus hojas.

Morfología de la Hoja: Las hojas de maracuyá suelen crecer hasta alcanzar 8 pulgadas de largo. Son individuales y alternas, de color verde, brillantes en la parte superior, y más pálidas y opacas por debajo. El maracuyá exhibe heteroblastía, lo que significa que hay una diferencia 
notable y una transición en la forma de la hoja con la edad de la misma: las hojas de plántulas jóvenes tienen forma ovalada, mientras que las hojas adultas son pronunciadamente lobuladas, con dos espacios, y finamente dentadas (Figura 4). Las hojas intermedias pueden tener rasgos tanto de hojas maduras como de hojas jóvenes. En la base de cada hoja existen nectarios florales adicionales (Figura 5), que secretan una solución azucarada que atrae insectos buscadores de néctar, como hormigas y abejas.

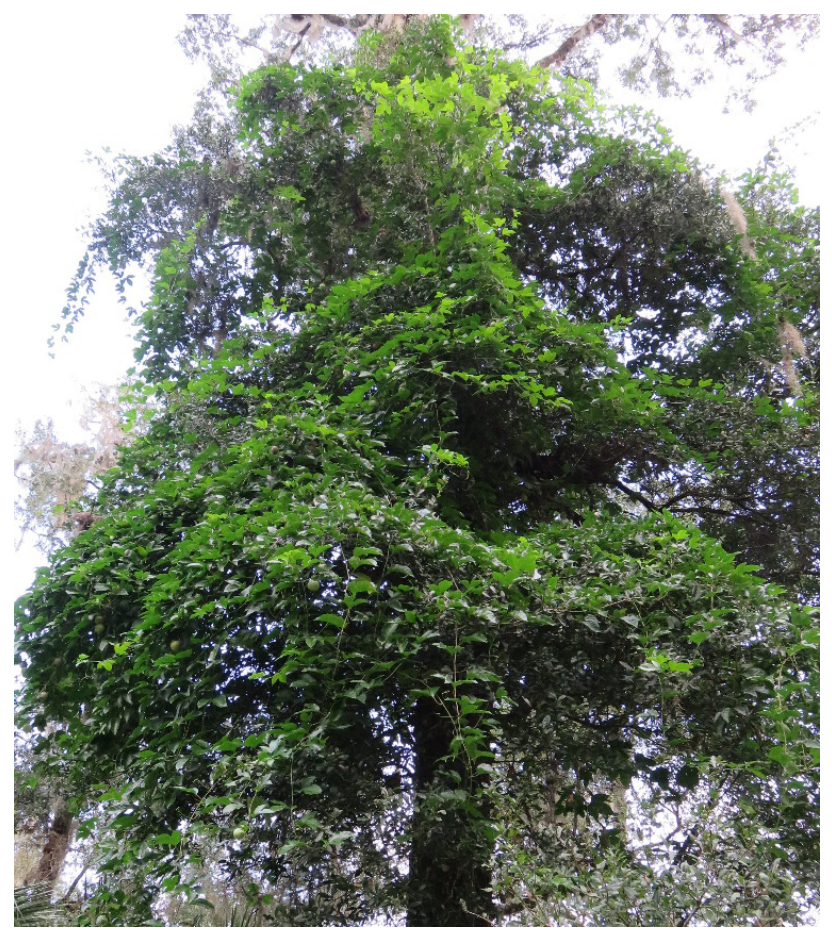

Figura 3. P. edulis 'Zarigüeya Púrpura' ('Possum Puprple') trepando a un árbol.

Créditos: Susan Bailey, UF/IFAS

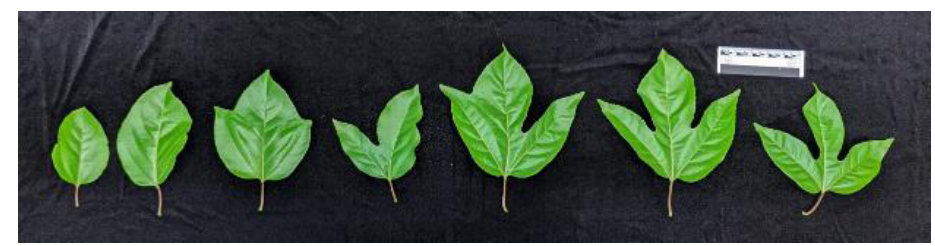

Figura 4. Heteroblastía de hojas en P. edulis desde plantas jóvenes a maduras. La transición de hojas jóvenes y de un solo lóbulo, a la izquierda, a hojas maduras con tres lóbulos, a la derecha. Créditos: Josh Anderson, UF/IFAS

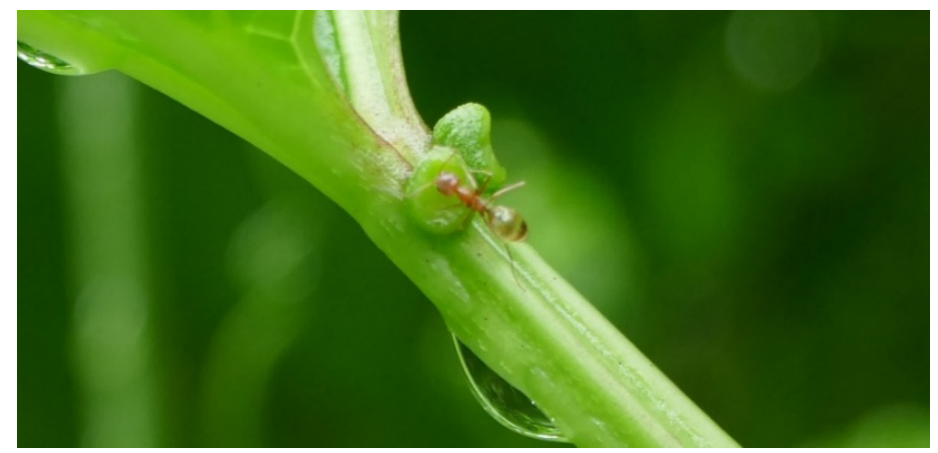

Figura 5. Hormiga alimentándose de néctar extrafloral. Créditos: Mark Bailey, UF/IFAS
Características y Morfología de la Flor: Las flores de maracuyá miden entre 2.5 a 3 pulgadas de ancho, son ligeramente fragantes, $y$ tienen la cara dirigida hacia afuera de la planta (Figura 6 y 7). Estas flores son perfectas, es decir, contienen partes masculinas y femeninas. La estructura de la flor (Figura 8) es pentámera, con 5 pétalos, 5 sépalos y 5 anteras. El óvulo se encuentra debajo del estigma de tres puntas, y se convertirá en un fruto de maracuyá si es polinizado adecuadamente. Debajo de la antera se encuentra el opérculo, que contiene néctar para atraer insectos. Existen muchos filamentos coronales creciendo desde el opérculo, que son de color púrpura oscuro cuanto más cercanos al centro, pero se tornan blancos a medida que se extienden hacia afuera. Debajo de los filamentos coronales son encuentran los 5 pétalos y los 5 sépalos. Los sépalos, que están debajo de los pétalos, se diferencian de estos últimos por la presencia de una punta verde. La gran abeja carpintera (Xylocopa spp.), que tiene un aspecto similar al de un abejorro (Figura 9), es el insecto más eficaz para polinizar el maracuyá. Otras abejas e insectos que se alimentan de néctar también pueden ayudar en la transferencia de polen de una flor a otra. Algunas variedades púrpuras pueden autopolinizarse, mientras que las variedades amarillas no se consideran capaces de esto, y los híbridos varían en su autocompatibilidad.

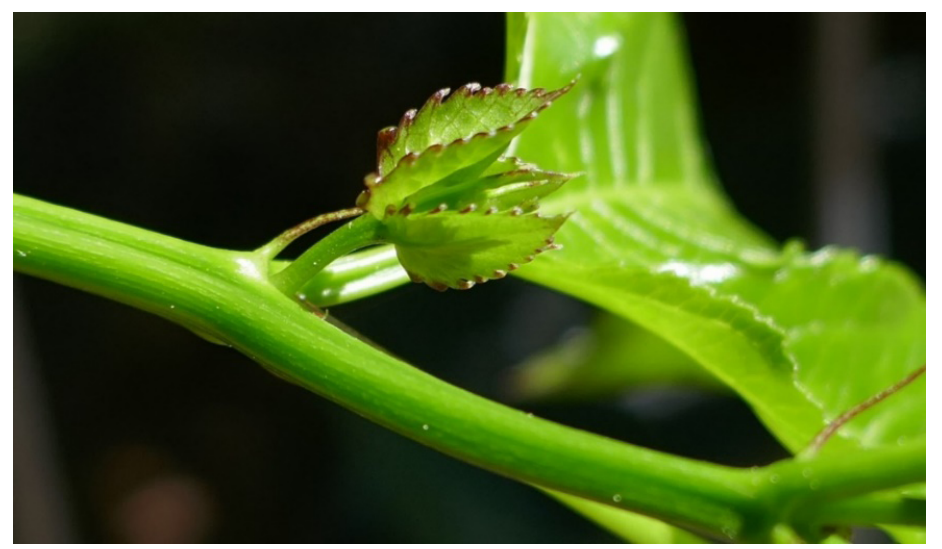

Figura 6. Nuevo botón florar emergiendo de tejido jóven. Créditos: Mark Bailey, UF/IFAS

Morfología de la Fruta: Las flores emergen del tejido nuevo (crecimiento reciente) y sólo producirán frutos si son polinizadas. La cantidad de pulpa está determina, en gran medida, por la calidad de la polinización. El fruto proviene del óvulo de la flor. Mientras la fruta verde e inmadura crece, vestigios de los sépalos y pétalos podrían ser retenidos (Figura 10). Al madurar, el fruto puede tener colores que van desde el púrpura oscuro o borgoña hasta el amarillo (Figura 11). La cáscara de tipo pepo rodea una médula blanca, lo que en conjunto puede ser clasificado botánicamente como una baya, llena de una pulpa que cubre semillas negras. La pulpa se compone de 
sacos membranosos, llamados arilos, rellenos de un jugo de color entre amarillo y naranja (Figura 12). La fruta ya madura típicamente mide entre 2.5 a 3 pulgadas de largo, $y$ alrededor de 2.25 pulgadas de ancho. Además, podría tener la forma de un huevo o forma redonda.

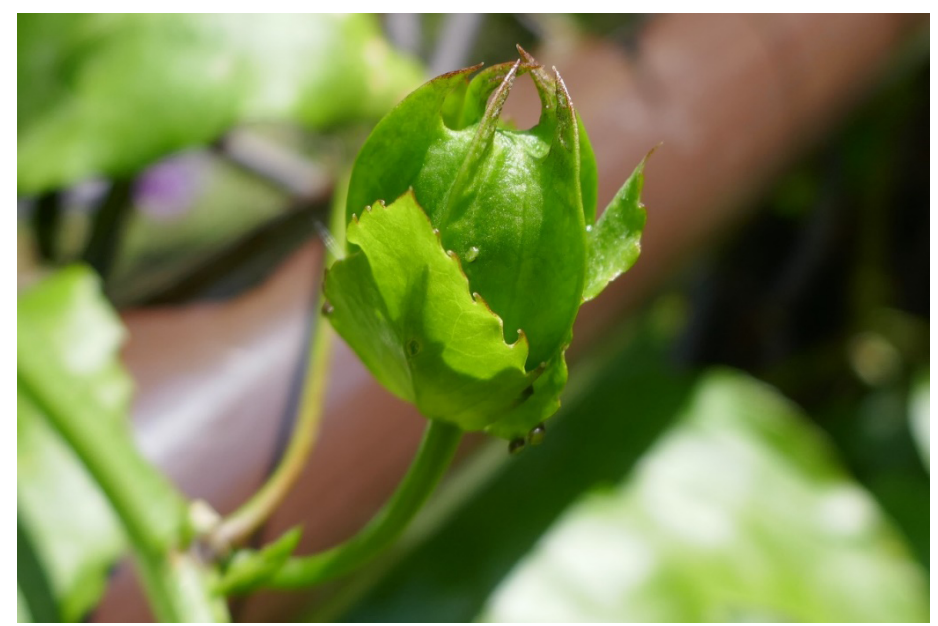

Figura 7. Botón floral cerca del periodo de floración. Créditos: Mark Bailey, UF/IFAS

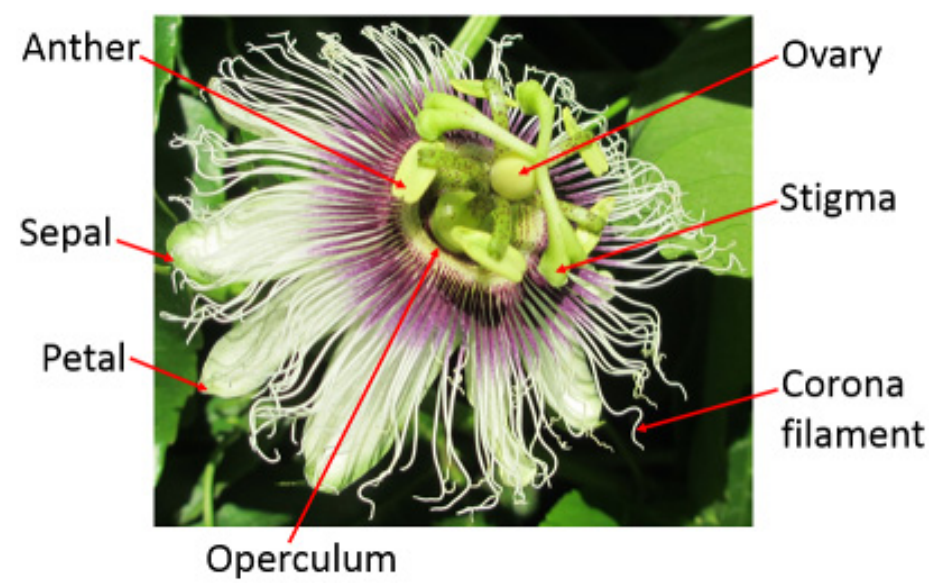

Figura 8. Anatomía de la flor del maracuyá.

Créditos: Mark Bailey, UF/IFAS

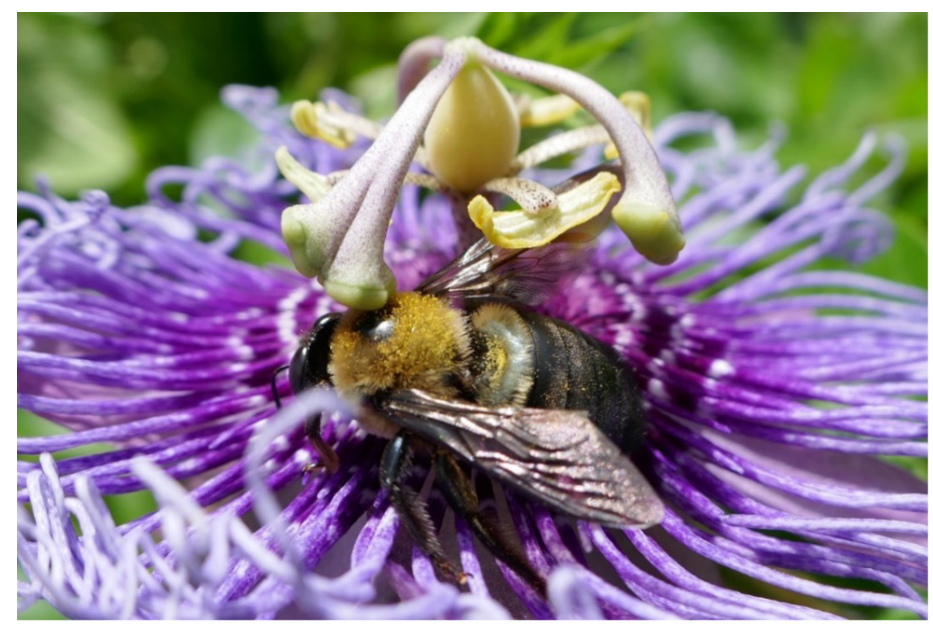

Figura 9. Xylocopa virginica (abeja carpintera oriental) cubierta de polen sobre flor de maracuyá ( $P$. incarnata).

Créditos: Mark Bailey, UF/IFAS

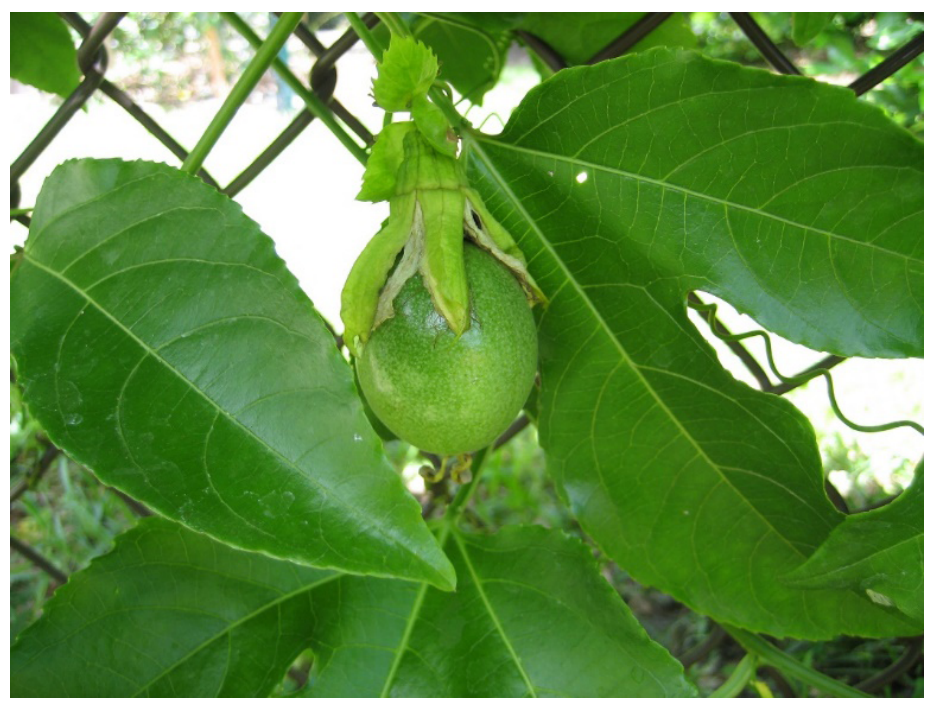

Figura 10. Maracuyá púrpura, inmaduro, y con vestigios de la flor. Créditos: Mark Bailey, UF/IFAS

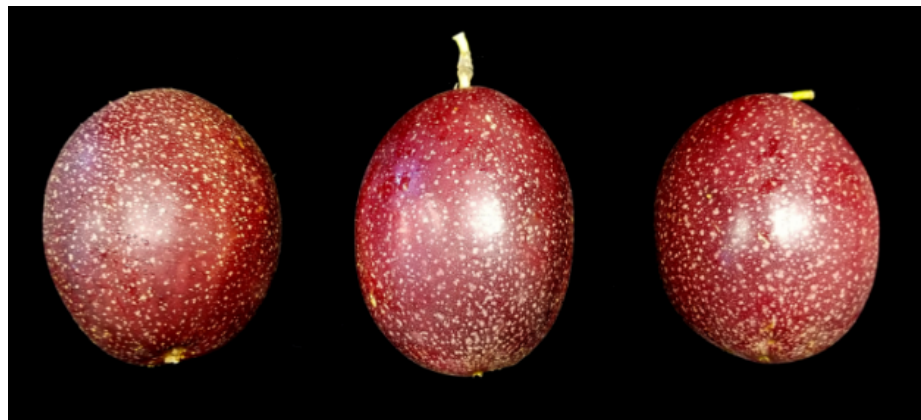

Figura 11. Fruto del maracuyá 'Rojo Panamá' ('Panama Red'). Créditos: Alan Chambers, UF/IFAS

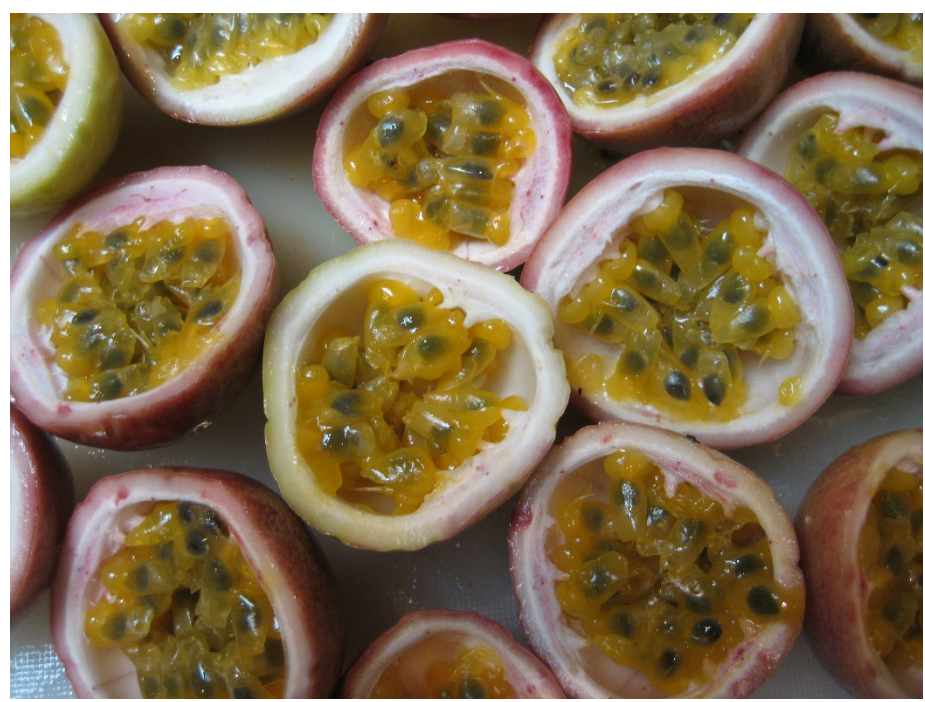

Figura 12. Sección transversal de un fruto de maracuyá, mostrando los arilos llenos de jugo y semillas negras.

Créditos: Mark Bailey, UF/IFAS

\section{Cultivares de Maracuyá}

Existen numerosas selecciones locales de maracuyá en Florida, siendo la mayoría híbridos entre maracuyás amarillos y morados [por ejemplo, los cultivares 'Rojo Panamá, 'Zarigüeya Púrpura' y 'Recompensa' ('Bounty’)]. 
Los productores comerciales típicamente seleccionan sus propias mejores plantas para injerto, las cuales propagan vegetativamente a través de esquejes enraizados o injertados en un portainjerto. Un cultivar de maracuyá se puede evaluar para características que incluyen tamaño de fruto, apariencia, resistencia a enfermedades, cantidad de pulpa o jugo, relación pulpa-piel, sabor, concentración de azúcar y acidez, y cualidades aromáticas. La información sobre características de los cultivares es limitada, pero lo que se conoce se menciona a continuación.

\section{'Zarigüeya Púrpura' ('Possum Purple')}

Una selección de plántulas de "Possum Trot Nursery" es el cultivar más ampliamente propagado y producido en el sur de la Florida (Figura 14). Las flores son autocompatibles. La cáscara tiene un color púrpura medio oscuro, con numerosos puntos claros que cubren la superficie. El fruto tiene entre 2.5 a 3.5 pulgadas de largo y alrededor de 2 pulgadas de diámetro. Además, el fruto tiene un aroma agradable y el jugo tiene un sabor dulce, moderadamente fuerte. Se requieren entre 70 a 75 días desde la floración hasta la cosecha.

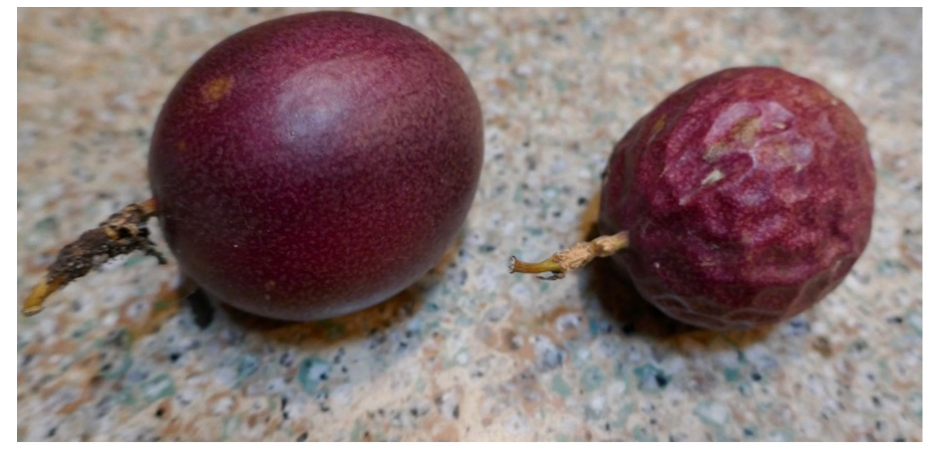

Figura 13. Fruto del maracuyá 'Zarigüeya Púrpura' ('Possum Purple'). El característico fruto arrugado se muestra a la derecha.

Créditos: Mark Bailey, UF / IFAS

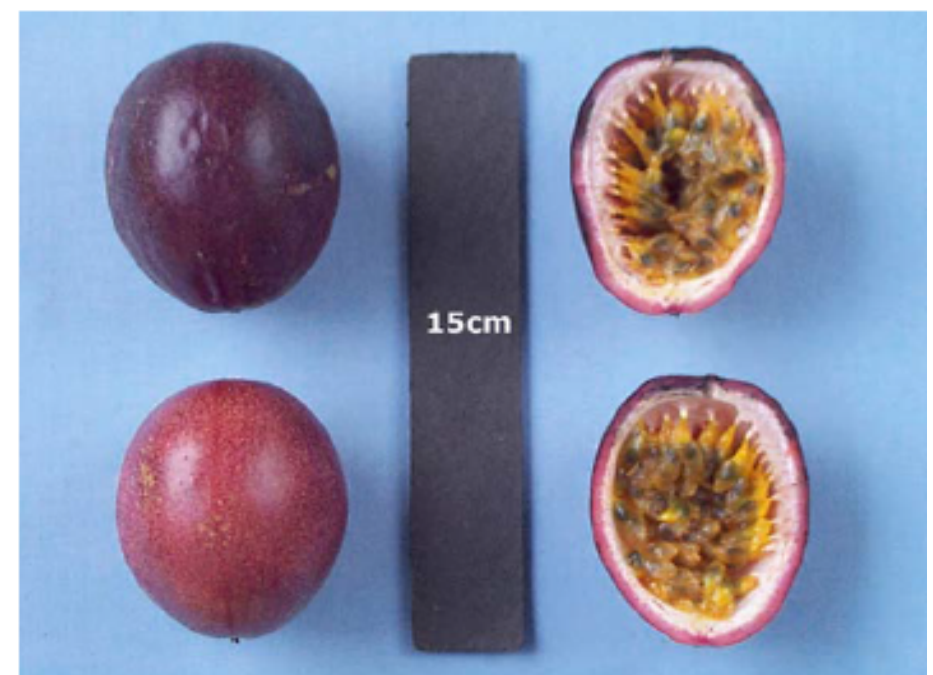

Figura 14. Fruto del maracuyá 'Zarigüeya Púrpura' ('Possum Purple'). Créditos: Jonathan Crane, UF/IFAS

\section{'Rojo Panamá' ('Panama Red')}

Como su nombre lo indica, el fruto de 'Rojo Panamá' es de color rojo cuando está maduro. Tiene forma ovalada. Fue probablemente seleccionado por productores australianos para obtener mayores rendimientos. El fruto de este cultivar puede ser más grande que el de 'Zarigüeya Púrpura' y tener un perfil de sabor similar.

\section{'Dulce Amanecer' ('Sweet Sunrise')}

El cultivar 'Dulce Amanecer' es de tipo amarillo, con un fruto del tamaño de una pelota de béisbol. Actualmente, es comercializado por viveros en el sur de Florida (Figura 15).

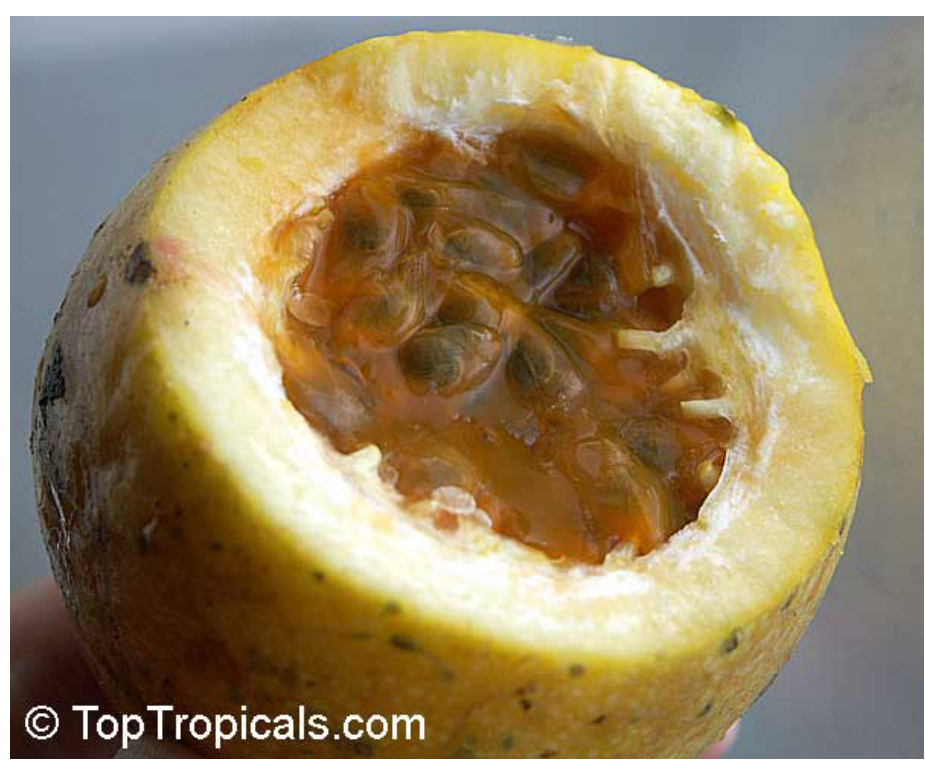

Figura 15. Maracuyá ‘Dulce Amanecer' ('Sweet Sunrise'). Créditos: Top Tropical

\section{'Amarillo Whitman' ('Whitman Yellow')}

Este cultivar fue seleccionado por William Whitman, un conocido entusiasta de las frutas tropicales de larga data, íntimamente involucrado en el cultivo de fruta tropical en el sur de Florida (Figura 16).

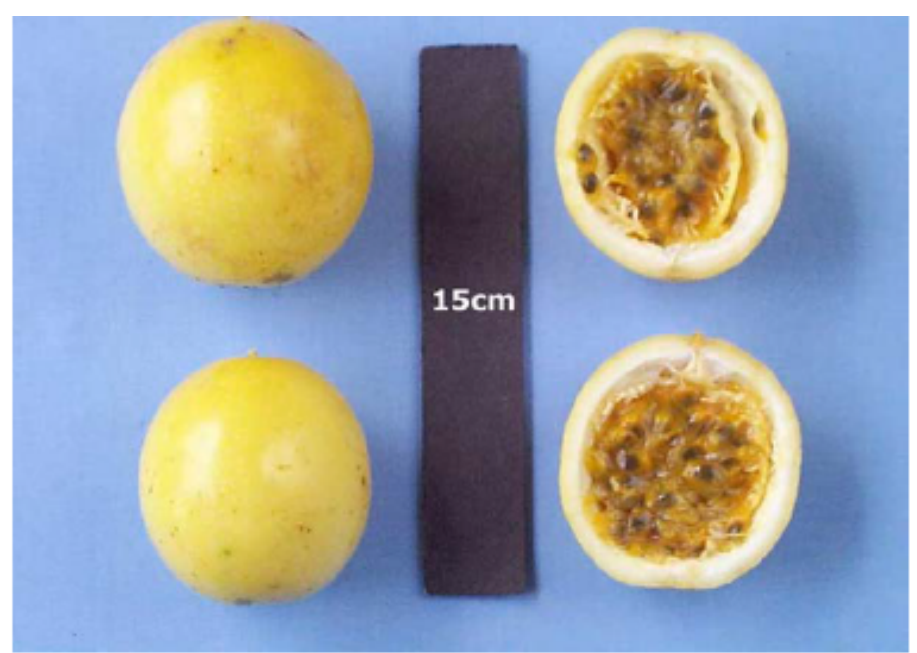

Figura 16. Maracuyá 'Amarillo Whitman' ('Whitman Yellow'). Créditos: Jonathan Crane, UF/IFAS 
Es posible que algunos cultivares de Hawái y Australia no estén actualmente disponibles en el sur de Florida. Algunos cultivares interesantes incluyen: 'Púrpura Australiano' ('Australian Purple'), 'Selecto de Don' ('Don's Choice'), 'Frederick, 'McGuffy', 'Gema Brumosa' ('Misty Gem'), 'Nellie Kelly,' 'Panama, 'Pandora, 'Mejilla Rosada' ('Pink Cheek'), 'Híbrido Pratt' ('Pratt Hybrid'), 'Flamenco rojo' ('Red Flemenco'), 'Rover Rojo' ('Red Rover'), 'Cariño' ('Sweetheart'), 'Tas Negro' ('Tas Black'), 'Especial de Tom' ('Toms Special'), y 'Selección de Waimanalao' ('Waimanalo Selection'). Los cultivares Amarillos incluyen 'Selección Kapoho' ('Kapoho Selection'), 'Selecto de Mike' ('Mike's Choice'), 'Dorado Panamá' ('Panama Gold'), 'Selecto de Sevcik' ('Sevcik Selection'), 'Selección Ronda Universitaria' ('University Round Selection'), 'Selección Universitaria No. B-74' ('University Selection No. B-74'), 'Whitman', y 'Selección de Yee' ('Yee Selection').

\section{Cultivo y Manejo}

Propagación: El maracuyá pueden propagarse a partir de esquejes, micropropagación, o semillas frescas. Sólo se debe utilizar material para trasplante libre de enfermedades, especialmente debido a la presencia de virus persistentes. Si se propagan a partir de semillas, deben ser lo más frescas posible y mantenerse en condiciones cálidas y húmedas para inducir la germinación. Mientras que las semillas frescas tendrán un porcentaje de germinación más alto que semillas más viejas, en general las semillas de maracuyá tienen porcentajes de germinación relativamente bajos en comparación con otros cultivos. La germinación puede mejorarse mediante la escarificación la testa de la semilla, cortando el borde de la semilla usando una hoja afilada y dejando la semilla en remojo, inmersa en agua, durante la noche. Las semillas se pueden sembrar en bandejas o macetas con suelo limpio o sustratos (medio) para cultivo, el cual debe mantenerse húmedo. Idealmente, condiciones de alta humedad son mejores, lo que se puede lograr cubriendo los contenedores de crecimiento con plástico o domos de humedad. Si se mantienen calientes (aproximadamente $85^{\circ} \mathrm{F}$ ), las semillas suelen germinar dentro de una semana y media a tres semanas. Después de la germinación, las plántulas deben mantenerse en sombra parcial, y no bajo luz solar directa, pues esto podría quemar las plántulas. Es recomendable transferir las plántulas de sombra parcial a sol parcial durante varios días antes de transferirlas a pleno sol.

El maracuyá puede propagarse mediante esquejes de plantas productivas saludables, seleccionadas cuidadosamente para evitar la propagación de plantas infectadas por virus (Figura 17). Esto se puede hacer cortando una porción de planta saludable con follaje activo. Para aumentar el éxito, se recomienda utilizar al menos dos nodos, y se pueden incluir hasta cuatro por corte. Después, se deben remover todas las hojas, excepto la superior, tomando en cuenta cuál de los extremos es la parte inferior del esqueje (con respecto a la dirección de crecimiento de la enredadera). La parte inferior del corte se puede sumergir en una hormona de enraizamiento, y luego plantar a una profundidad de 2 a 4 pulgadas en sustrato para cultivo limpio. El ambiente debe mantenerse húmedo (con domos de humedad, bolsas de plástico o sprays intermitentes), bajo luz indirecta. El sustrato o medio de cultivo debe ser humedecido regularmente. En condiciones óptimas, los esquejes pueden estar listos para plantarse en tres o cuatro meses. Es importante proteger los esquejes de insectos, para reducir la probabilidad de infecciones virales.

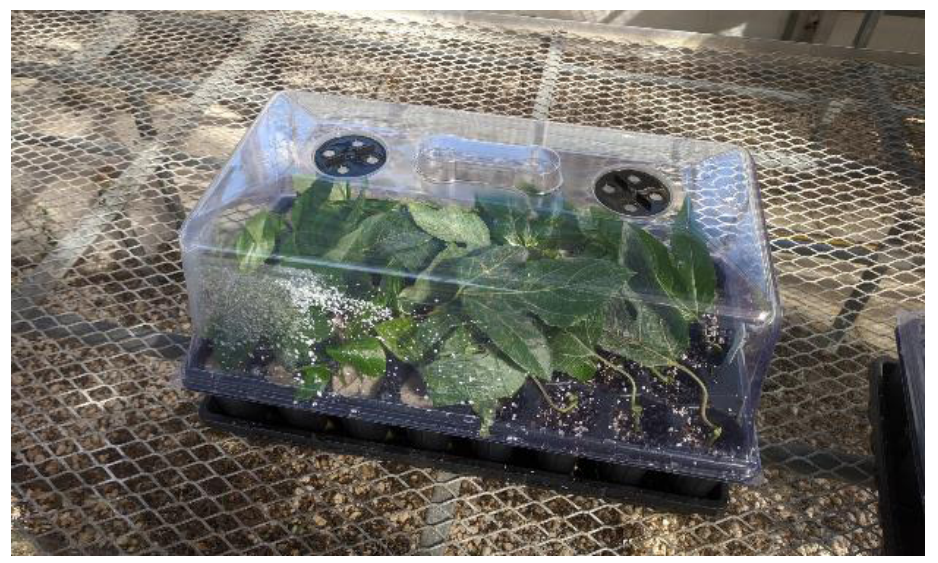

Figura 17. P. edulis recortes en una bandeja honda cubierta por un domo de humedad.

Créditos: Joshua Anderson, UF/IFAS

Injerto: El maracuyá púrpura puede ser injertado en un portainjerto de maracuyá amarillo, lo que podría ayudar a reducir problemas por enfermedades| que afectan el sistema radicular de cultivares susceptibles. Las plántulas del injerto y portainjerto deben tener aproximadamente 18 pulgadas de largo y aproximadamente 0.25 pulgadas de diámetro de tallo cuando se seleccionan para injertar. Los esquejes deben tener entre 3 a 4 pulgadas de largo y contener al menos 2 nodos al momento de ser cortados para injertar. El portainjerto debe cortarse entre 10 a 12 pulgadas por encima de la línea del suelo. Varias técnicas de injerto se pueden aplicar haciendo una hendidura, incluyendo injertos de látigo y lengua, silla de montar, y chapa. El aspecto más importante del injerto es alinear el cambium vascular de ambas plantas y mantener la unión firme y en su lugar, envolviendo con parafina o cinta para injerto. Es importante mantener la planta injertada regada, en un lugar cálido, y con luz indirecta por un periodo de 10 a 14 días, o hasta que el injerto pegue. El envoltorio se puede remover cuando la herida del injerto ha sanado completamente. 
Ubicación: El maracuyá crece mejor a pleno sol, o en un lugar donde pueden recibir pleno sol después de crecer. Las enredaderas de maracuyá deben plantarse en suelos bien drenados, y pueden tolerar condiciones de $\mathrm{pH}$ neutro o ligeramente alcalino ( $\mathrm{pH}$ 6-7.5). Sin embargo, suelos ligeramente ácidos son los mejores para producción de maracuyá.

\section{Plantación, Infraestructura y Riego: En áreas con tem-} peraturas potencialmente de congelación o frías $\left(<50^{\circ} \mathrm{F}\right)$, las plantas jóvenes pueden trasplantarse a principios de primavera, cuando no existe riesgo de heladas. En zonas con temperaturas entre cálidas y calurosas $\left(<90^{\circ} \mathrm{F}\right)$, las plantas pueden trasplantarse en cualquier momento, siempre y cuando el riego esté disponible durante los períodos secos.

Para plantaciones paisajísticas domésticas, se puede utilizar una cerca simple pero fuerte, o un sistema de tutoreo que pueda soportar fuertes vientos aun cubierto con la enredadera. Para producción comercial, existen numerosos diseños y configuraciones de tutoreo. Un método común es el sistema de tutoreo vertical, con un espacio entre hileras de 10 a 15 pies. El espaciado entre plantas dentro de la hilera varía de 6 a 10 pies. Las hileras deben plantarse de norte a sur para maximizar la exposición a la luz solar.

Cobertura del suelo, mulch plástico o mulch convencional se pueden utilizar para suprimir malezas y mantener la humedad del suelo. Una alternativa a la plantación directa en suelo nativo es utilizar bolsas de cultivo, lo que permite regular la mezcla de sustrato, libre de nematodos y enfermedades. Generalmente, las plantas cultivadas en contenedores se colocan sobre un soporte (por ejemplo, bloques de cemento) para facilitar el drenaje y evitar el contacto directo con el suelo.

Para paisajismo doméstico, las enredaderas de maracuyá pueden ser regadas con pequeños aspersores o instalando un sistema de riego por goteo. Aunque no es necesario, es útil tener temporizadores programables con información del clima y un medidor de lluvia, lo que permitiría regular el sistema y minimizar la frecuencia y cantidad de riego.

Las plantaciones comerciales utilizan líneas de goteo por encima del mulch plástico, o también riego con microaspersores para minimizar el uso de agua y mantener al máximo la productividad de la planta. El maracuyá necesita poco riego, pero frecuente, para garantizar que se mantenga una humedad adecuada en el suelo, pero sin llegar a la saturación. Los sensores de humedad de suelo (por ejemplo, tensiómetros y sensores capacitivos) y el monitoreo de las condiciones meteorológicas mejorarán los programas de riego, minimizarán las tasas de irrigación, y reducirán las probabilidades de lixiviar agua y nutrientes por debajo de la zona radicular.

Formación y Poda: Después de plantar nuevas matas, estas deben entrenarse para crecer a lo largo de los alambres del sistema de tutoreo. Posteriormente, las enredaderas se adherirán naturalmente a cualquier objeto que los zarcillos pueden envolver (Figura 18 y 19). Dependiendo del diseño del sistema de tutoreo, las plantas deben ser entrenadas para crecer de manera que se maximice el área superficial del dosel. Una alternativa es un sistema de entrenamiento de "cortina", en el que un tallo principal alcanza el cable de soporte superior, con enredaderas extendiéndose horizontalmente y luego cayendo como una cortina para rellenar el espacio disponible de abajo.

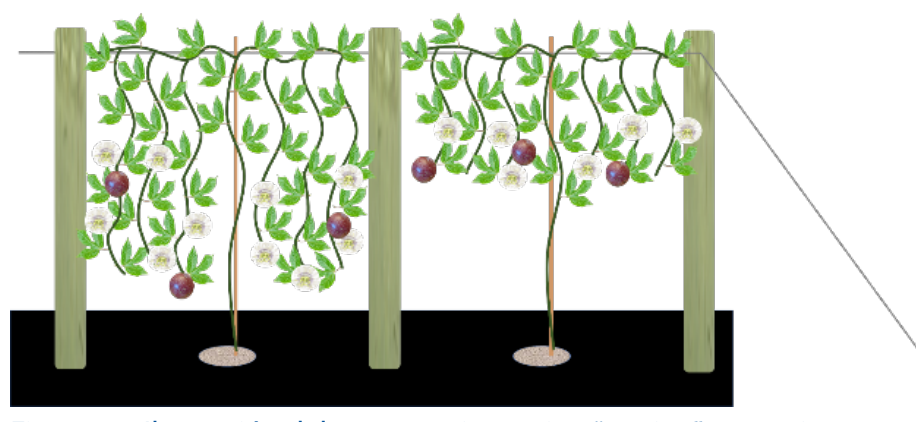

Figura 18. Ilustración del entrenamiento tipo "cortina" en un sistema de tutoreo vertical; etapa más avanzada a la izquierda. Créditos: Josh Anderson, UF/IFAS

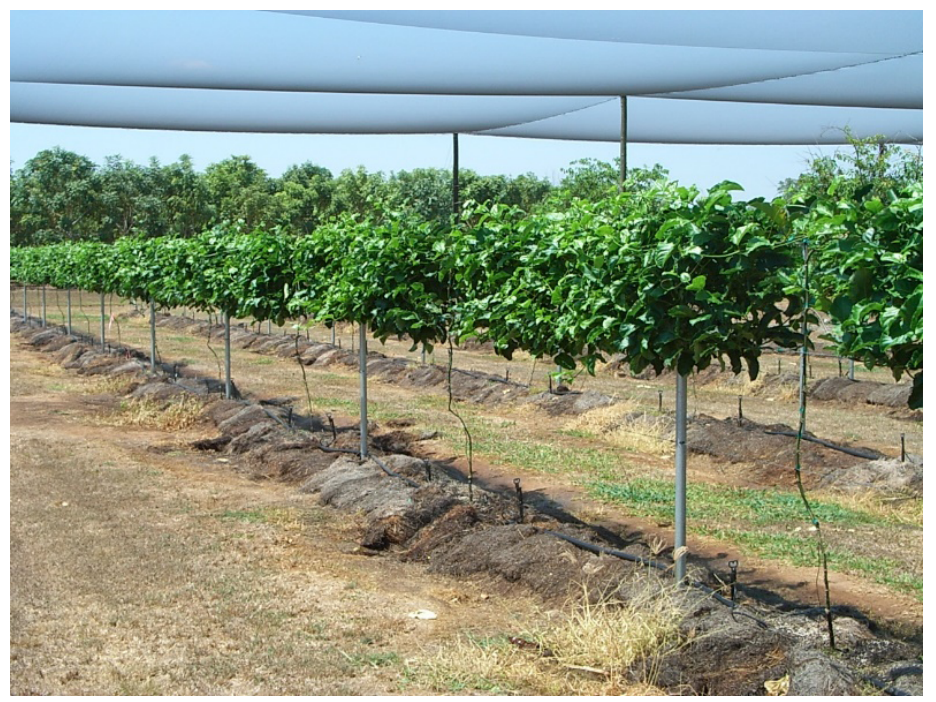

Figura 19. Entrenando enredaderas de maracuyá en un sistema de tutoreo vertical.

Créditos: Ali Sarkhosh, UF/IFAS

Las enredaderas deben podarse a finales del invierno, cuando no están creciendo activamente. Se recomienda usar una solución de lejía al 10\%, o amonio cuaternario, para desinfectar las herramientas de poda entre cada planta, y así evitar la propagación de enfermedades. Con el tiempo, 
si se deja sin manejo, el crecimiento nuevo de la enredadera puede volverse denso y cubrir partes más antiguas que pierden sus hojas, formando un dosel pajoso compuesto de hojas muertas. Esto puede ser una fuente de enfermedades fúngicas, que afectan negativamente a las nuevas hojas y la calidad del fruto. Las enredaderas de maracuyá pueden podarse hasta volver al tallo principal, o a ramas saludables creciendo del tallo principal. Todos los tallos muertos y débiles deben ser podados, y se debe buscar tener tallos vigorosos en la planta para que puedan reanudar un crecimiento saludable y activo a inicios de la primavera. Un buen momento para realizar la primera aplicación de fertilizante es después de la poda.

\section{Estrés Ambiental}

Estrés por frío: Las temperaturas óptimas para el crecimiento y la producción varían según la especie y tipo de maracuyá (Menzel y Simpson 1994). En general, las temperaturas entre $65^{\circ} \mathrm{F}$ y $90^{\circ} \mathrm{F}$ son las mejores para el crecimiento de la planta y la producción de frutos; temperaturas fuera de este rango pueden resultar en una reducción del crecimiento, floración, viabilidad del polen, y producción de frutos. Las plantas maduras con follaje adecuado pueden tolerar temperaturas varios grados bajo cero, pero pueden morir completamente con exposición prolongada a temperaturas de congelación $\left(32^{\circ} \mathrm{F}\right)$ o por debajo de este punto $\left(20-25^{\circ} \mathrm{F}\right)$ (Campbell et al. 1977). Las enredaderas de maracuyá también pueden sufrir daños por frío con temperaturas por debajo de $59^{\circ} \mathrm{F}$ y sobre $32^{\circ} \mathrm{F}$ (Menzel y Simpson 1994). La experiencia en la protección de las enredaderas de maracuyá contra heladas sugiere que el uso de coberturas con alta capacidad de aislamiento (por ejemplo, aislante consistente en guata de fibra de vidrio de alto valor $\mathrm{R}$ ) alrededor de la base de la planta pueden proteger esta área de daños por bajas temperaturas. Brotes nuevos podrían crecer a partir de esta área después de la helada. Las envolturas aislantes deberían removerse después de la helada.

Un sistema de riego de alto volumen de agua correctamente diseñado puede proteger las enredaderas de maracuyá de las heladas. Por lo general, se utilizan aspersores giratorios $\left(360^{\circ}\right)$ de alto volumen colocados por encima del sistema de tutoreo, con un espaciamiento adecuado para permitir una cobertura completa con agua sobre las plantas. Esta estrategia protege con éxito las enredaderas de maracuyá durante heladas ocurridas al sur de la Florida (J. H. Crane, comunicación personal). Los sistemas deben instalarse y cuidarse correctamente. Deben encenderse cuando las temperaturas de campo alcancen los $36^{\circ} \mathrm{F}$, y dejarse encendidos hasta que las temperaturas de bulbo húmedo alcancen más de $32^{\circ} \mathrm{F}$ al día siguiente. Por favor, póngase en contacto con su agente local de extensión de UF/IFAS para obtener más información.

Estrés por Sequía: Las enredaderas de maracuyá y la producción de fruta son sensibles a condiciones de sequía en el suelo. El estrés por sequía se traduce en un menor crecimiento, menor floración, cuaje reducido y tamaño de fruto reducido (Menzel y Simpson 1994; Turner et al. 1996). Investigaciones recientes han demostrado que las condiciones de sequía también aumentan la susceptibilidad de las plantas a enfermedades transmitidas por el suelo, causadas por la especie fúngica Fusarium (Lima et al. 2019). El estrés por sequía severo resulta en defoliación, caída de los frutos, y muerte de la enredadera.

Guía de Fertilizantes: Durante el primer año, una planta joven debe fertilizarse para fomentar el máximo crecimiento de raíces y enredaderas (Tabla 1). La máxima producción de fruta generalmente comienza después de un año completo de crecimiento. Los fertilizantes comunes, como el 10-10-10 u 8-3-9, pueden proporcionar nutrientes necesarios como nitrógeno, fósforo y potasio. Es importante proporcionar también nutrientes secundarios y micronutrientes para maximizar la salud de las plantas y la calidad de los frutos. Los nutrientes secundarios incluyen magnesio y azufre, y los micronutrientes incluyen boro, níquel, manganeso, cobre, zinc y hierro. Los nutrientes pueden aplicarse mediante fertirrigación (fertilizante líquido aplicado a través de líneas de riego), como también fertilizante granular, o a través de aplicaciones foliares. Si se utiliza fertilizante granular, pequeñas cantidades (entre $0.25 \mathrm{a} 1 \mathrm{lb} /$ planta) deben aplicarse desde finales del invierno hasta el otoño, en intervalos de 4 a 6 semanas (Cuadro 1). Estos intervalos pueden durar hasta julio en el norte de Florida, mientras que pueden continuar hasta octubre en el sur. Para enredaderas que crecen en suelos de alto $\mathrm{pH}(>7)$, nutrientes secundarios y micronutrientes se pueden aplicar foliarmente o en forma quelada al suelo. Las aplicaciones de hierro quelado son muy importantes para las plantas que crecen en suelos calcáreos de $\mathrm{pH}$ alto. Un fertilizante quelado, como Sequestrene ${ }^{\circledast} 138$ (6\% Fe-EDDHA), es una buena opción. Se recomienda mezclar el polvo con agua y empapar el área cerca de la base de las plantas de 2 a 4 veces por año. Después del primer año de crecimiento, la cantidad de fertilizante nitrogenado debe reducirse sustancialmente para facilitar la floración, en lugar de un crecimiento vegetativo excesivo. 


\section{Floración, Polinización y Fructificación}

En el sur de Florida, el maracuyá florece y produce frutos desde la primavera hasta el otoño o principios de invierno, dependiendo del cultivar (Figura 20). En la región norte de la parte central de Florida, la floración suele ocurrir en primavera, y los frutos maduran en pleno verano. La polinización es esencial para la producción de frutos. Las flores del maracuyá púrpura pueden polinizarse a sí mismas, mientras que muchos híbridos de maracuyá púrpura y amarillo pueden o no ser de este tipo. Las enredaderas de maracuyá amarillo no son autopolinizables, y requieren polen de una planta compatible, genéticamente diferente. Si se utilizan cultivares autoincompatibles de maracuyá, se sugiere plantar dos cultivares diferentes en la misma zona para fomentar la polinización y el cuaje de frutos. Mientras que las abejas carpinteras se encuentran comúnmente en el norte y centro de Florida, rara vez son observadas en el sur del estado. La polinización manual con un guante de algodón limpio, o un pincel, es una forma laboriosa pero eficaz de garantizar la producción de frutos. El tiempo desde floración hasta cosecha es generalmente de 70 a 75 días.
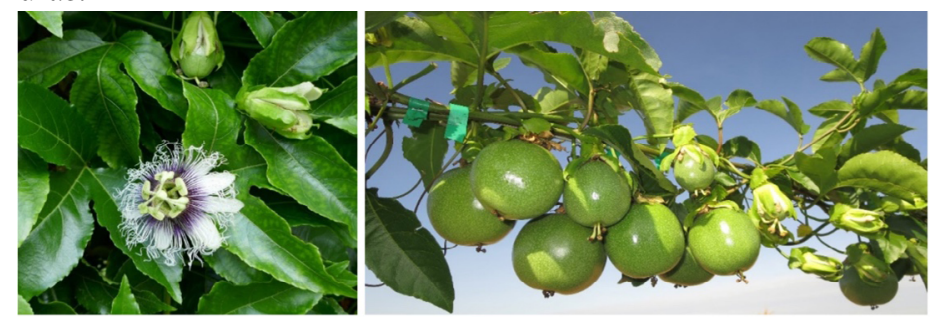

Figura 20. Desarrollo de flores y frutos.

Créditos: Mark Bailey y Ali Sarkhosh, UF/IFAS

\section{Cosecha y Almacenamiento}

Una planta de maracuyá puede producir entre $5 \mathrm{a} 15 \mathrm{lb}$ de fruta. El pico de producción ocurre a mediados del verano en todo el estado de Florida. El rendimiento total de maracuyá obtenido de un acre oscila entre 2,200 lb y 4,400 lb por acre (Knight and Sauls 1994), lo que corresponde a entre 18,000 a 35,000 frutas. Una vez que los frutos estén maduros, estos caerán al suelo, lo que no daña el fruto de piel gruesa (Figura 20 y 21). Aunque la fruta puede recogerse directamente de la planta, es difícil asegurar que esté completamente madura en el interior. El fruto inmaduro tiene un aroma y sabor inferiores. Los frutos caídos deben recogerse regularmente para mantener la calidad en postcosecha. El fruto es firme cuando está maduro, pero con el tiempo se arrugará a medida que pierde agua, principalmente de la cáscara. Esto puede disminuir el valor comercial del fruto, aunque todavía es comestible (Figura 13).

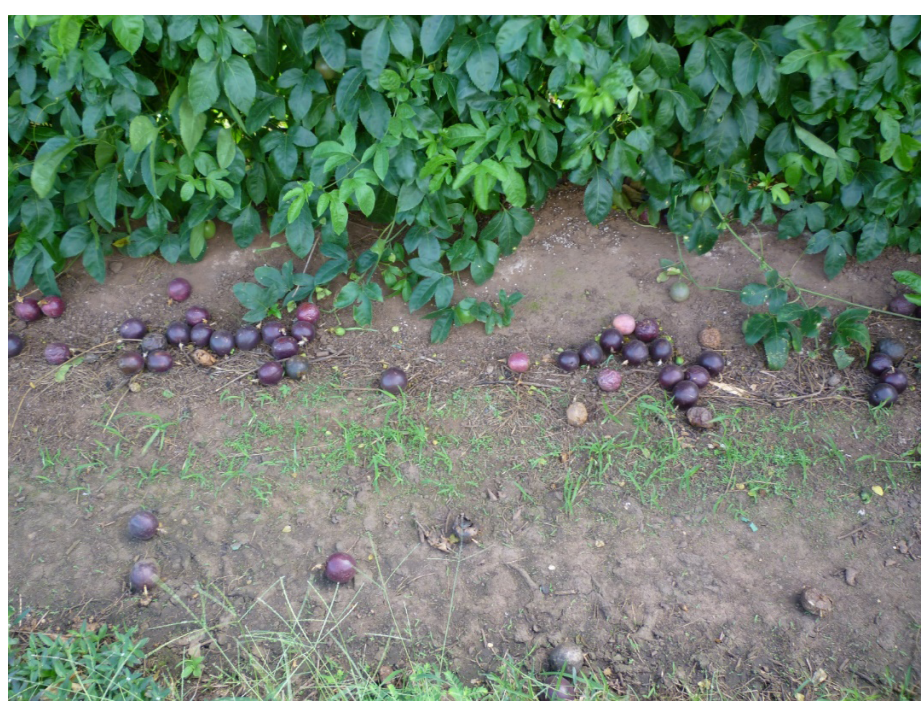

Figura 21. Frutos de maracuyá caídos en el suelo. Créditos: Ali Sarkhosh, UF/IFAS

Los residuos florales a menudo permanecerán en el tallo de la fruta y pueden eliminarse fácilmente. En general, la fruta fresca puede almacenarse hasta dos o más semanas en bolsas de plástico a $41^{\circ} \mathrm{F}-54^{\circ} \mathrm{F}$ y $85 \%-90 \%$ de humedad relativa (Bora y Narain 1997; Paull y Chen 2016). La caída de frutos maduros al suelo puede causar preocupaciones sobre contaminación cruzada. Para controlar esto, los productores deben consultar con los consumidores con respecto a sus expectativas sobre prácticas seguras de manejo.

\section{Plagas y Enfermedades}

El maracuyá puede ser afectado por varias plagas de insectos, ácaros, nematodos y patógenos vegetales, además de enfermedades fúngicas y virales, que pueden causar daños significativos a las plantas y frutos (Figura 22). Las larvas de varias especies de mariposas (Lepidoptera) pueden defoliar completamente las enredaderas, si no se controlan.

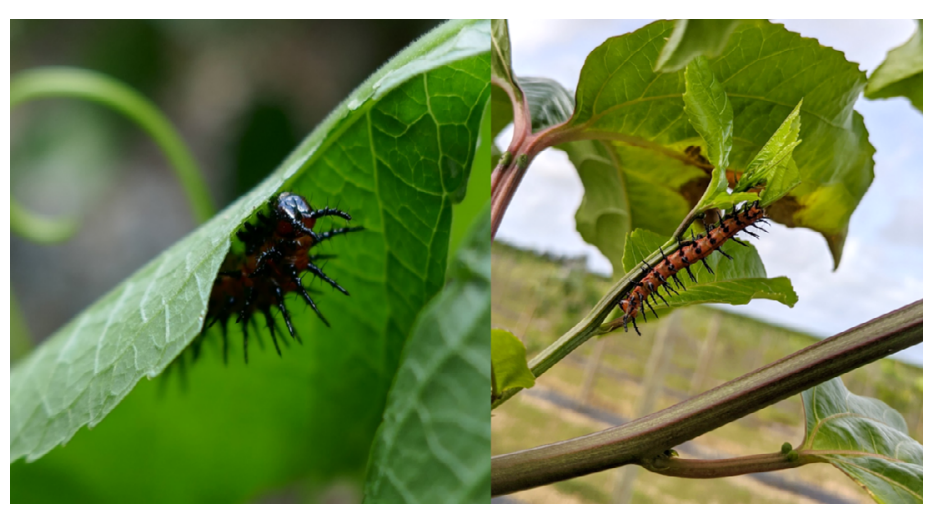

Figura 22. Oruga Speyeria del Golfo alimentándose de hojas. Créditos: Mark Bailey y Joshua Anderson, UF/IFAS

Las chinches hediondas ocasionalmente perforan el fruto y causan daños menores en la cosecha. Los ácaros araña también pueden causar defoliación severa, lo que conduce 
a la muerte si las enredaderas están en áreas con pocos depredadores naturales para estos insectos (Figura 23). Varios insecticidas y fungicidas están registrados para su uso comercial en maracuyá. Sin embargo, es fundamental la selección adecuada de productos a aplicar, y evitar que estas aplicaciones maten insectos polinizadores y abejas nativas. Por favor, póngase en contacto con su Oficina Local de Extensión de UF/IFAS para obtener más información y orientación sobre este tema.

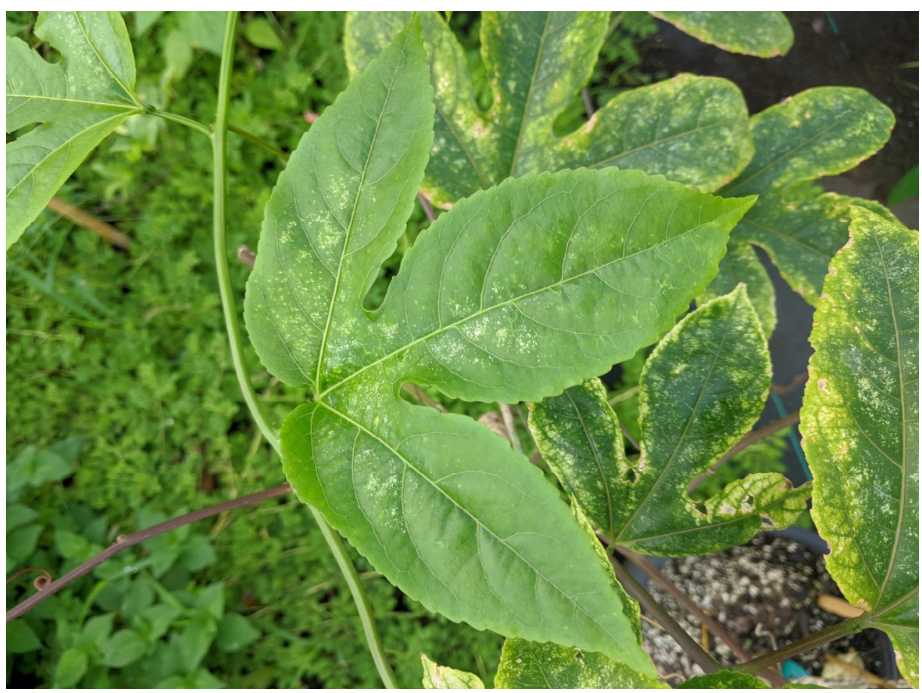

Figura 23. Daño producido por el ácaro araña. Nótese el daño en hojas jóvenes comparado con el daño en hojas más viejas.

Créditos: Joshua Anderson, UF/IFAS

Es más probable que los nematodos parásitos (gusanos microscópicos) ataquen el sistema radicular del maracuyá púrpura que el del maracuyá amarillo. Los síntomas incluyen marchitamiento, crecimiento reducido, $y$ atrofiamiento o malformación de las raíces. En Florida, el maracuyá púrpura a veces es injertado en portainjertos de maracuyá amarillo para mitigar el daño a las raíces por hongos y nematodos.

Existen varios patógenos importantes que pueden dañar o matar toda la planta y afectar la calidad del fruto y el rendimiento (Figura 24, 25 y 26). El principal patógeno sospechoso en plantaciones de maracuyá en el sur de la Florida es el hongo Fusarium solani, que causa el cáncer por Fusarium (Ploetz 1991). Los síntomas de cáncer incluyen marchitamiento repentino de las hojas, las cuales manifiestan síntomas de clorosis y permanecen unidas a la planta junto con los frutos afectados. Además, el tejido moribundo alrededor de la base del tallo puede eventualmente anillar y cortar el tallo completo a nivel del suelo. Esto puede estar asociado a la podredumbre de la raíz, hinchazón del tallo por el cáncer, y crecimiento de raíces adventicias. Vasos vasculares descoloridos son generalmente visibles a menos de 2 pies de donde se observa el cáncer (Manicom et al. 2003).

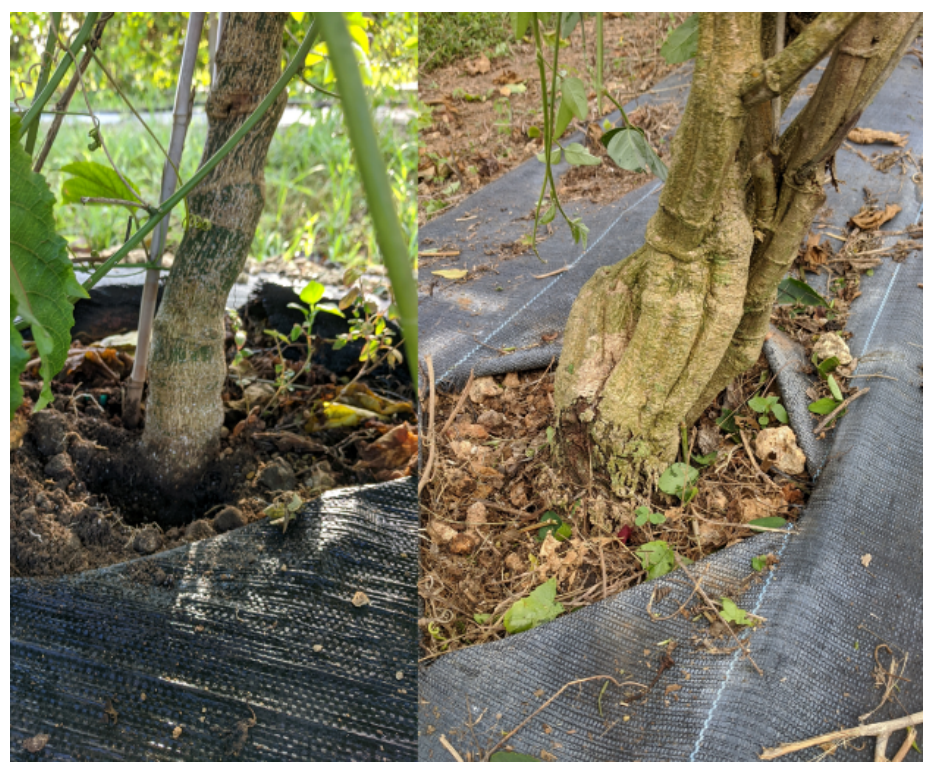

Figura 24. Comparación de un tallo sano de un portainjerto de maracuyá amarillo, a la izquierda, con una plántula de maracuyá amarillo con cáncer, a la derecha, donde se observa hinchazón y muerte de la corteza exterior.

Créditos: Joshua Anderson, UF/IFAS

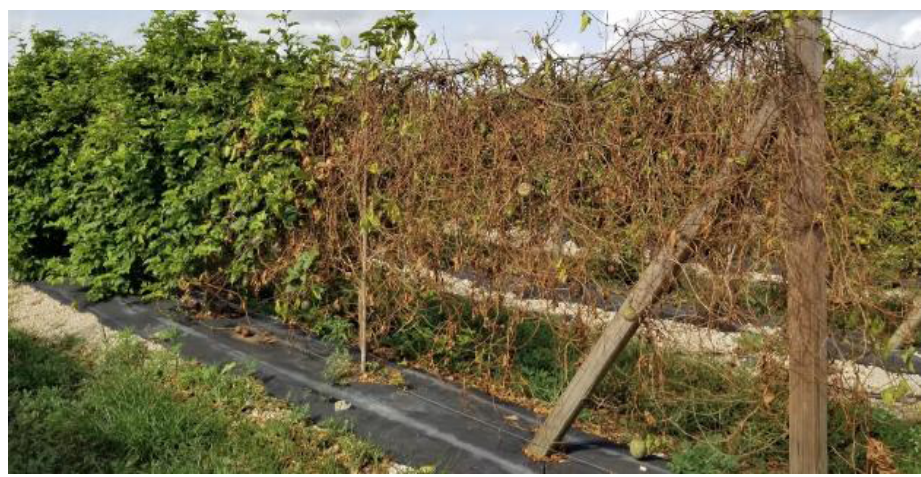

Figura 25. Enredaderas de maracuyá muertas como consecuencia del ataque de patógenos al sistema radicular.

Créditos: Alan Chambers, UF/IFAS

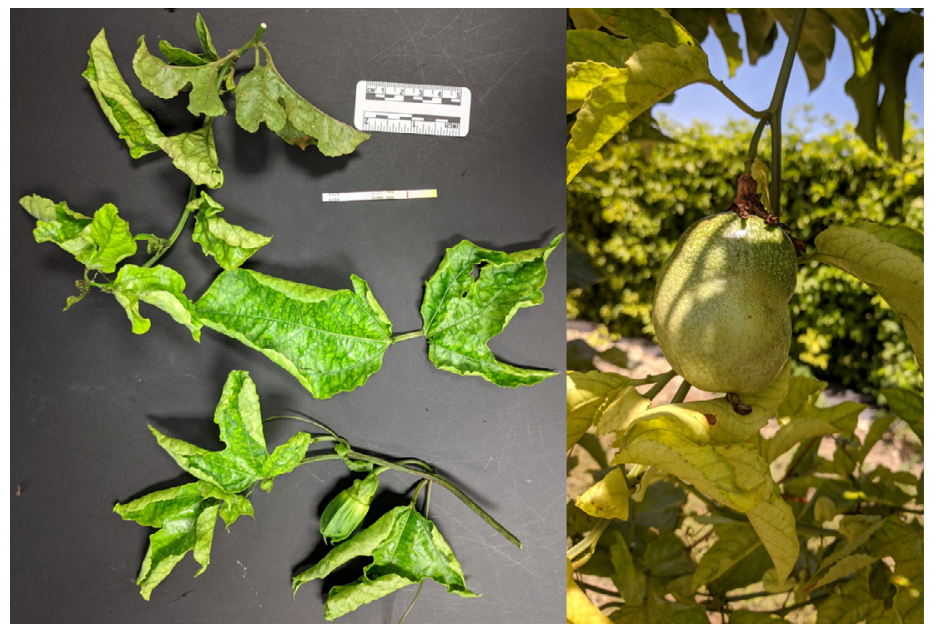

Figura 26. Síntomas del Potyvirus: A la izquierda, mosaico en las hojas, motas, enrollamiento, y deformación; a la derecha, fruto deformado con hojas cloróticas.

Créditos: Joshua Anderson, UF/IFAS 
El hongo patógeno Alternaria puede atacar a las hojas y el fruto, causando manchas. Los patógenos Phytophthora (similar a los hongos) se alimentan de las raíces y de la base del tallo de las plantas, causando la podredumbre de la corona o collar de la raíz, defoliación y finalmente la muerte, precedida por un engrosamiento del collar radicular, clorosis leve (que a veces parece una quemadura en la hoja) y marchitez (Fischer y Rezende 2008). El fruto también se ve afectado por lesiones acuosas grisáceas o verdosas. Controlar las enfermedades del maracuyá transmitidas por el suelo se complica aún más en suelos con un drenaje pobre.

En casos donde las plantas mueren o son gravemente afectadas por patógenos, lo mejor es eliminarlas y reemplazarlas con plantas nuevas y saludables. Si una planta murió a causa de un patógeno transmitido por el suelo, lo mejor es no plantar en el mismo lugar para evitar que el patógeno persista.

Las plantas en el vivero no deben estar en contacto directo con el suelo, donde podrían exponerse a nematodos u hongos. Si las enredaderas de maracuyá están creciendo sobre un sistema de tutoreo, es importante no permitir la acumulación de hojas y ramas muertas, pues esto aumentará en gran medida las posibilidades de desarrollo de enfermedades en hojas y especialmente en frutos. En casos en que las infecciones por hongos se esperan en hojas $y$ frutos, el uso responsable de fungicidas registrados puede hacerse de forma preventiva. Por favor, póngase en contacto con su Oficina Local de Extensión de UF/IFAS para obtener más información.

Algunos virus (por ejemplo, el virus leñoso del maracuyá) pueden ser importantes factores limitantes para el establecimiento y el crecimiento de las plantas de maracuyá. Las infecciones por virus no se pueden curar en condiciones de campo, y son consideradas como el posiblemente factor más limitante para la producción de maracuyá en todo el mundo. Los virus del maracuyá son una amenaza considerable en Florida (Baker et al. 2014; Elliott et al. 1991; Fischer y Rezende 2008). Las especies de Potyvirus (por ejemplo, virus del mosaico del caupi transmitido por áfidos, CABMV) causan la enfermedad del maracuyá leñoso (Nascimento et al. 2006). Los síntomas incluyen defoliación, hojas deformadas con patrones de mosaico o moteado, y fruto endurecido (leñoso) y deforme (Figure 26). Por el momento, no se han reportado genotipos resistentes a las infecciones de CABMV (Costa et al. 2020). Los virus generalmente son transmitidos por pulgones, pero también a través de material para trasplante infectado (por ejemplo, esquejes), $\mathrm{y}$ algunos pueden ser transmitidos incluso por semillas. Es esencial utilizar semillas limpias o plantas nuevas, libres de enfermad. El material de propagación debe ser analizado para detectar la presencia de virus antes de su uso. Antes de comenzar a cultivar una nueva planta o plantación, todo el material infectado en la zona debe ser descartado. Si la presión de enfermedades es alta en un área en particular, es aconsejable buscar nuevas áreas para plantación, aisladas de áreas antiguas.

\section{El Maracuyá como Alimento}

El jugo de maracuyá es una fuente de fibra dietética, ácido ascórbico (vitamina C), carotenoides (vitamina A), riboflavina, hierro, potasio y niacina (Percival y Findley 2007; USDA ARS 2020) (Figura 27). El maracuyá es famoso por sus cualidades aromáticas agradables y sabor rico, ácido, y con matices frutales. La pulpa del fruto se puede consumir cruda junto con las crujientes semillas. El jugo sin diluir tiene un sabor fuerte y es un excelente aditivo para otros jugos y bebidas. También se puede utilizar en alimentos como mermeladas, gelatinas, glaseados, helados, y rellenos de pastelería.

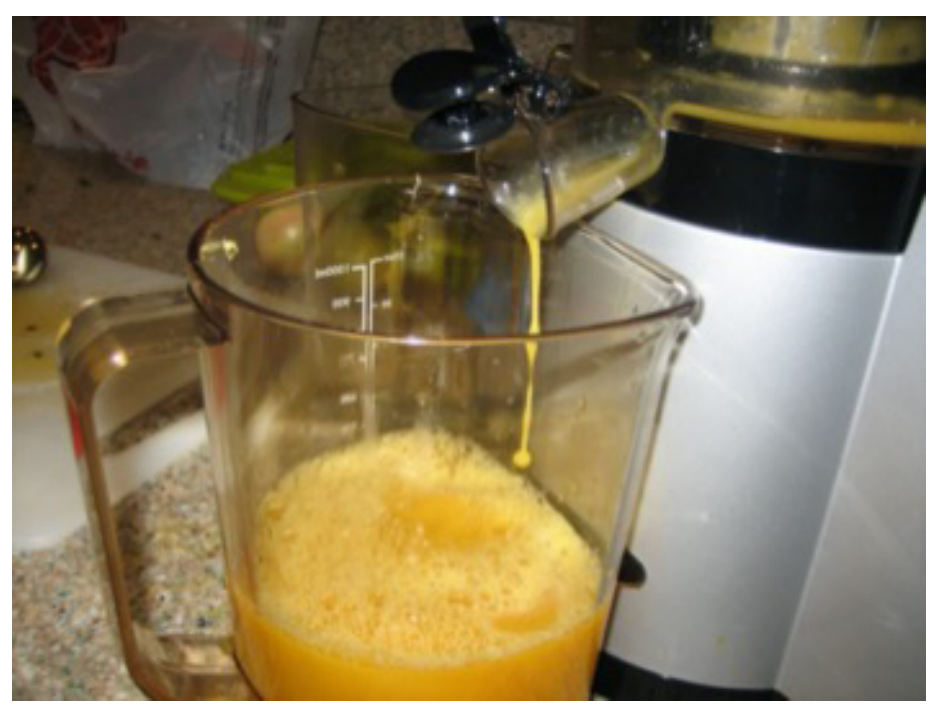

Figura 27. Extracción de jugo de maracuyá con un exprimidor. Créditos: Susan Bailey, UF/IFAS

\section{Comercialización}

El maracuyá se cultiva en la mayoría de las regiones ecuatoriales del mundo y, a menudo, donde existe un mercado establecido. Se comercializa como jugos, concentrados, y fruta cruda. Florida, California y Hawái contribuyen la mayoría de la producción nacional de fruta fresca, aunque la mayor parte es importada a los Estados Unidos. Se ha reportado que la fruta en el mercado mayorista oscila entre 0.75 y 2.00 dólares por fruto, dependiendo de las condiciones del mercado y otras variables (USDA, Agricultural Marketing Service 2020). Los frutos se pueden comercializar 
individualmente, en contenedores de plástico, o en bandejas para una docena (o múltiplos de una docena). Las opciones de venta al por menor son por cantidad o por peso. La fruta también se vende directamente a los clientes a través de los mercados de agricultores y en línea (enviada a los compradores), o al por mayor para los mercados minoristas.

\section{Literatura Citada}

Altendorf, S. 2018. "Minor Tropical Fruits: Mainstreaming a Niche Market." FAO Food Outlook, July 2018. Accessed August 29, 2020. http://www.fao.org/3/ca0239en/ CA0239EN.pdf

Baker, C. A., A. Jeyaprakash, C. G. Webster, and S. Adkins. 2014. "Viruses Infecting Passiflora Species in Florida." Florida Dep. Agric. Consum. Serv. Plant Pathol. Circ.

Baumgartner, J. G. 1987. "Nutrição e adubação.” In Maracujá, edited by C. Ruggiero, 86-96. São Paulo, Brazil: UNESP (São Paulo State University).

Bernacci, L. C., M. D. Soares-Scott, N. T. V. Junqueira, I. R. da S. Passos, and L. M. M. Meletti. 2008. "Passiflora edulis Sims: The Correct Taxonomic Way to Cite the Yellow Passion Fruit (and of Others [sic] Colors)." Rev. Bras. Frutic. 30 (2): 566-576. https://doi.org/10.1590/ s0100-29452008000200053

Bora, P. S., and N. Narain. 1997. "Passion Fruit.” In Postharvest Physiology and Storage of Tropical and Subtropical Fruits, edited by S. K. Mitra, 375-386. New York, NY: CAB International.

Campbell, C. W., R. J. Knight, Jr., and N. L. Zareski. 1977. "Freeze Damage to Tropical Fruits in Southern Florida in 1977." Proc. Fla. State Hort. Soc. 90:254-257.

Costa, A. P., I. Nogueira, J. R. Peixoto, and L. E. B. Blum. 2020. "Screening of Sour Passion Fruit for Reaction to Bacterial Spot and Passion Fruit Woodiness Disease." J. Agric. Sci. 12 (2): 130-137. https://doi.org/10.5539/jas. v12n2p130

Elliott, M. S., F. W. Zettler, and J. H. Crane. 1991. "Surveys for Viruses of Passiflora Spp. Which Threaten the Passionfruit Industry in South Florida." Proc. Fla. State Hort. Soc. 104:49-50.

Fischer, I. H., and J. A. M. Rezende. 2008. "Diseases of Passion Flower (Passiflora spp.)." Pest Technology 2 (1): 1-19.
FLEPPC. 1999. “1999 List of Invasive Plant Species.” Florida Exotic Pest Plant Council. Accessed August 30, 2020. https://www.fleppc.org/list/list.htm

FLEPPC. 2019. “2019 List of Invasive Plant Species.” Florida Exotic Pest Plant Council. Accessed August 29, 2020. https://www.fleppc.org/list/list.htm

Knight, R. J., Jr. and J. W. Sauls. 1994. The Passion Fruit. HS60. Gainesville: University of Florida Institute of Food and Agricultural Sciences. https://ufdc.ufl.edu/ IR00003395/00001

Knight, R. J. 1972. "The Potential for Florida of Hybrids between the Purple and Yellow Passionfruit." Florida State Hortic. Soc. 85:288-292.

Knight, R. J., and H. F. Winters. 1962. "Pollination and Fruit Set of Yellow Passionfruit in Southern Florida." Florida State Hortic. Soc. 75:412-418.

Lima, L. K. S., O. N. de Jesus, T. L. Soares, S. A. S. de Oliveira, F. Haddad, and E. A. Girardi. 2019. "Water Deficit Increases the Susceptibility of Yellow Passion Fruit Seedlings to Fusarium Wilt in Controlled Conditions." Sci. Hortic. 243:609-621. https://doi.org/10.1016/j. scienta.2018.09.017

Manicom, B., C. Ruggiero, R. C. Ploetz, and A. de Goes. 2003. "Diseases of Passion Fruit." In Diseases of Tropical Fruit Crops, edited by R. C. Ploetz, 413-441. Cambridge, MA: CABI. https://doi.org/10.1079/9780851993904.0413

Menzel, C. M., G. F. Haydon, V. J. Doogan, and D. R. Simpson. 1993. "New Standard Leaf Nutrient Concentrations for Passionfruit Based upon Season Phenology and Leaf Composition." J. Horticultural Science 68:215-230.

Menzel, C. M., and D. R. Simpson. 1994. "Chapter 10. Passionfruit." In Handbook of Environmental Physiology of Fruit Crops, Vol. II: Subtropical and Tropical Crops, edited by B. Schaffer and P. C. Andersen, 225-241. Salem, MA: CRC Press, Inc.

Nascimento, A. V. S., E. N. Santana, A. S. K. Braz, P. F. Alfenas, G. Pio-Ribeiro, G. P. Andrade, M. G. de Carvalho, and F. Murilo Zerbini. 2006. "Cowpea aphid-borne mosaic virus (CABMV) is Widespread in Passionfruit in Brazil and Causes Passionfruit Woodiness Disease." Archives of Virology 151:1797-1809. https://doi.org/10.1007/ s00705-006-0755-6 
Newett, S., J. Daniells, and P. Rigden. 1999. “Growing the Crop." Passionfruit Information Kit Annual Update, Agrilink Series QAL9802. Dept. of Primary Industries, Nambour, Queensland, Australia.

Paull, R. E., and C. C. Chen. 2016. "Passion Fruit." In USDA-ARS Agric. Handbook Number 66. The Commercial Storage of Fruits, Vegetables and Florist and Nursery Stocks, edited by K. C. Gross, C. Y. Wang, and M. Saltveit, 460-462. Washington, D.C.

Percival, S. S., and B. Findley. 2007. What's in Your Tropical Fruit? FSHN07-08. Gainesville: University of Florida Institute of Food and Agricultural Sciences. https://journals.flvc. org/edis/article/view/116933

Ploetz, R. C. 1991. "Sudden Wilt of Passionfruit in Southern Florida Caused by Nectria haematococca." Plant Dis. 75:1071-1073. https://doi.org/10.1094/pd-75-1071

Queensland Department of Agriculture and Fisheries. 2016. "Managing Passionfruit Plantations Affected by Wet Weather." QLD. Dep. Agric. Fish. 1-4.

Rooney-Latham, S., C. L. Blomquist, and H. J. Scheck. 2011. "First Report of Fusarium Wilt Caused by Fusarium oxysporum f. sp. passiflorae on Passion Fruit in North America." Plant Dis. 95 (11): 1478. https://doi.org/10.1094/ pdis-03-11-0261

Silva, G. S., and M. M. Santos. 2020. "Origin of the Cultivated Passion Fruit Passiflora edulis f. flavicarpa and Genomic Relationships among Species of the Subgenera Decaloba and Passiflor." Plant Biol. 22 (3): 533-540. https:// doi.org/10.1111/plb.13100

Turner, D. W., C. M. Menzel, and D. R. Simpson. 1996. "Short Term Drying of Half the Root System Reduces Growth but No Water Status or Photosynthesis in Leaves of Passion Fruit (Passiflora sp.)." Scientia Horticulturae 65:2536. https://doi.org/10.1016/0304-4238(95)00849-7

Ulmer, T., and J. M. MacDougal. 2004. Passiflora: Passionflowers of the World. Portland, OR: Timber Press.

USDA Agricultural Marketing Service. 2020. https://www. marketnews.usda.gov/mnp/fv-report-top-filters?locName= $\&$ commAbr=PASSIONF-V\&commName $=$ PASSION\%20FR UIT\&className $=$ FRUITS \&rowDisplayMax $=25 \&$ startInde $\mathrm{x}=1$ \&navClass $=$ FRUITS\&navType $=$ byComm\&repType $=$ ter

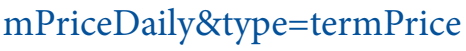

USDA ARS. 2020. "Passion Fruit Juice, 100\%: Nutrients." FoodData Central. https://fdc.nal.usda.gov/fdc-app.html\#/ food-details/1102755/nutrients

USDA ARS OSU. 2012. Plant Hardiness Zone Map. USDA. gov.

Wunderlin, R. P., B. F. Hansen, A. R. Franck, and F. B. Essig. 2020. "Passiflora." In Atlas of Florida Plants. Tampa: Institute for Systematic Botany, University of South Florida. Accessed August 29, 2020. https://florida.plantatlas.usf.edu/ Genus.aspx?id=891 
Tabla 1. Guía de niveles de nutrientes en hojas y fertilización para plantas de maracuyá en Florida'

\begin{tabular}{|c|c|c|c|c|c|}
\hline Nutriente & Rango & Nutriente & Rango & Nutriente & Rango \\
\hline \multicolumn{6}{|c|}{$\begin{array}{l}\text { Contenido de nutrientes en las hojas: Datos obtenidos de la hoja más joven completamente expandida (madura) antes de una ola de } \\
\text { crecimiento vegetativo, tomada a finales de invierno, antes de la ola de crecimiento }{ }^{\text {a }} \text {. }\end{array}$} \\
\hline $\mathrm{N}$ & $4.25 \%-5.25 \%$ & $\mathrm{Mg}$ & $0.20 \%-0.40 \%$ & $\mathrm{Fe}$ & 100-200 ppm \\
\hline$P$ & $0.15 \%-0.25 \%$ & $S$ & $0.2 \%-0.4 \%$ & $\mathrm{Cu}$ & $5-20 \mathrm{ppm}$ \\
\hline $\mathrm{K}$ & $2.00 \%-3.00 \%$ & $\mathrm{Mn}$ & $100-500$ ppm & $\mathrm{B}$ & 40-60 ppm \\
\hline \multirow[t]{2}{*}{$\mathrm{Ca}$} & $1.75 \%-2.75 \%$ & $\mathrm{Zn}$ & 50-80 ppm & $\mathrm{Na}$ & $<0.15 \%$ \\
\hline & & & & $\mathrm{Cl}$ & $<1.5 \%$ \\
\hline Meses de edad & $\begin{array}{l}\text { Frecuencia de } \\
\text { aplicación }\end{array}$ & $\begin{array}{l}\text { Cantidad (oz) de } \\
\text { NPK por planta }\end{array}$ & $\begin{array}{l}\text { Cantidad (lb) de } \\
\text { NPK para } 84 \text { plantas }\end{array}$ & $\begin{array}{c}\text { Elementos foliares } \\
\text { menores (oz) } 0.29 \\
\text { acres }^{d}\end{array}$ & $\begin{array}{c}\text { Hierro quelado } \\
\text { aplicado al suelo } \\
\text { para } 84 \text { plantas } \\
\text { (oz) }\end{array}$ \\
\hline \multicolumn{6}{|c|}{ Cronograma para fertilización ${ }^{b}$} \\
\hline $1-2$ & Cada 4 semanas & 4 & 21 & 10 & 21 \\
\hline 3 & Cada 4 semanas & 4 & 21 & 10 & \\
\hline 4 & Cada 4 semanas & 6 & 31.5 & 10 & 21 \\
\hline 5 & Cada 4 semanas & 6 & 31.5 & 10 & \\
\hline 6 & Cada 4 semanas & 6 & 31.5 & 10 & 21 \\
\hline 7 & Cada 4 semanas & 6 & 31.5 & 10 & \\
\hline 8 & Cada 6 semanas & 10 & 52.5 & 10 & 21 \\
\hline 9 & Cada 6 semanas & 10 & 52.5 & 10 & \\
\hline 10 & Cada 6 semanas & 10 & 52.5 & 10 & 21 \\
\hline 11 & Cada 6 semanas & 10 & 52.5 & 20 & \\
\hline $12+$ & Cada 6 semanas & 16 & 52.5 & 20 & 21 \\
\hline \multicolumn{6}{|c|}{ 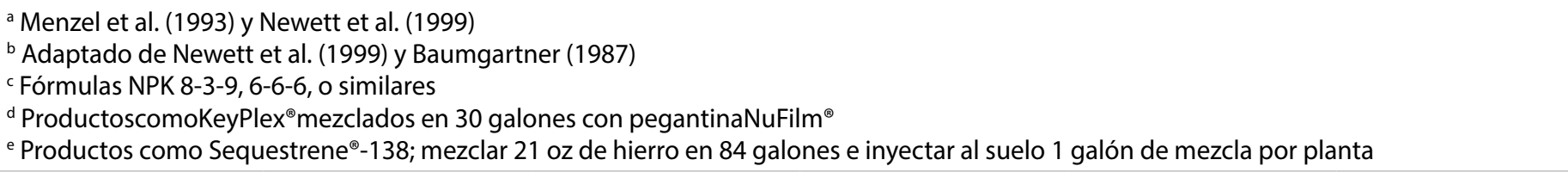 } \\
\hline
\end{tabular}

